\title{
Provider Continuity in Family Medicine: Does It Make a Difference for Total Health Care Costs?
}

Jan M. De Maeseneer, $M D^{1}$

Lutgarde De Prins, $M A^{1}$

Christiane Gosset, $M D^{2}$

Jozef Heyerick, $M D^{1}$

'Department of General Practice and Primary Health Care, Ghent University, Ghent, Belgium

${ }^{2}$ School of Public Health, University of Liège, Liège, Belgium

Conflict of interest: none reported

\section{CORRESPONDING AUTHOR}

Jan M. De Maeseneer, MD

Department of General Practice

and Primary Health Care

University of Ghent

De Pintelaan 185

Ghent, B-9000 Belgium

jan.demaeseneer@rug.ac.be

\begin{abstract}
BACKGROUND International comparisons of health care systems have shown a relationship at the macro level between a well-structured primary health care plan and lower total health care costs. The objective of this study was to assess whether provider continuity with a family physician is related to lower health care costs using the individual patient as the unit of analysis.
\end{abstract}

METHODS We undertook a study of a stratified sample of patients (age, sex, region, insurance company) for which 2 cohorts were constructed based on the patients' utilization pattern of family medicine (provider continuity or not). Patient utilization patterns were observed for 2 years. The setting was the Belgian health care system. The participants were 4,134 members of the 2 largest health insurance companies in 2 regions (Aalst and Liège). The main outcome measures were the total health care costs of patients with and without provider continuity with a family physician, controlling for variables known to influence health care utilization (need factors, predisposing factors, enabling factors).

RESULTS Bivariate analyses showed that patients who were visiting the same family physician had a lower total cost for medical care. A multivariate linear regression showed that provider continuity with a family physician was one of the most important explanatory variables related to the total health care cost.

CONCLUSIONS Provider continuity with a family physician is related to lower total health care costs. This finding brings evidence to the debate on the importance of structured primary health care (with high continuity for family practice) for a cost-effective health policy.

Ann Fam Med 2003;1:144-148. DOI: 10.1370/afm.75.

\section{INTRODUCTION}

$\mathrm{R}$ esearch on global characteristics of health care systems indicates that having a strong level of primary health care is cost-effective In a cross-national study, Starfield ${ }^{1}$ showed that countries with a well-developed primary health care system (eg, Sweden, the Netherlands) received generally high ratings on health indicators and satisfaction of their populations in relation to overall costs of the system. Patient lists and gatekeeping by the family physician help to structure health care delivery. Moreover, a family physician that knows a patient for a long time might perform more cost-effectively at the level of both diagnosis and therapy. There is some theoretical reason to expect the gatekeeping structure to be more cost-effective. ${ }^{2}$ Until now most of the evidence in this debate has come from cross-national comparisons at the macro level.

This article deals with what Starfield ${ }^{3}$ has called longitudinality: "a long-term personal relationship between practitioners and patients in 
their practice." This important aspect of continuity in primary care has raised some attention in the literature, and in the United States longitudinality is an issue in the debate on health care organization preferences. Looking at the individual behavior of patients, a study reviewing all claims of a random sample of Medicaid patients (aged 0 to 21 years) for 3 years showed that continuity with the same practitioner was associated with a significant reduction in the number of hospital admissions and overall costs. ${ }^{4}$ A more recent study, which included children as well as nonelderly adults, showed that patients with better provider continuity for 1 year had significantly lower rates of hospitalization in the subsequent year. ${ }^{5}$ A study conducted among emergency department patients found having a relationship with a regular physician to be a stronger predictor of increased access to all health care than insurance status. ${ }^{6}$ In a previous study we found a relationship between provider continuity and total costs, but the question of whether the relationship was attributable to differences in morbidity could not be resolved. ${ }^{7}$

In the present study, we analyzed, at the patient level, the relation between provider continuity with a family physician and total direct health care costs in Belgium, where there is no required enrollment of patients with family physicians and no patient list or gatekeeping system. The relationship between provider continuity in family practice and total health care costs is of importance for countries like the United States because of the problem of forced discontinuity resulting from changing health care plans. ${ }^{8}$

In Belgium, patients may consult any family physician for any problem at any time. Family physicians work in community-based, mostly solo practices $(80 \%)$ and provide general primary health care. About $45 \%$ of the physician-patient encounters are home visits. Patients pay the physician for every visit (fee for service) and are reimbursed about $70 \%$ by their health insurance company. Patients may go spontaneously to a medical specialist or to a hospital for specific problems. Extensive administrative databases are available from the different health insurance companies. Those databases make it possible to determine, for example, whether patients always visit the same family physician and what the total health care costs are at the individual level.

In this study we view provider continuity (always visiting the same family physician or not) as a possible explaining variable in a multidimensional behavioral model and ask the following research question: Is there, at the level of the individual patient, a relationship between provider continuity in family practice and total costs of medical care?

\section{METHODS}

A sample of 4,800 adults was randomly selected from the databases of the 2 largest health insurance providers after stratification for age (45 to 64, 65 to 74 , and 75 years and older), sex, region (Aalst and Liège), and insurance company. Each of the 24 subgroups included 200 persons. This design facilitates direct comparisons of subpopulations stratified for factors known to influence health care utilization. We restricted the study to the population older than 45 years of age because this group is known to have a higher utilization rate of medical services. The health insurance providers (A and $B$ ) cover more than $75 \%$ of the Belgian population. Aalst and Liège are 2 comparable regions, the former in the Dutch-speaking part of the country, the latter in the French-speaking part.

In total, 7,461 persons were contacted to provide 4,800 respondents, who gave informed consent. "Not interested" was the major reason for nonparticipation. Other reasons for nonparticipation were randomly distributed. No selection bias was found.

Interviews at home, conducted by trained interviewers from April 1995 until September 1995, collected information on living condition, lifestyle, morbidity, functional status, and opinions and perceptions about health and health care. Persons who refused to participate or were not found at home at 3 different times (including an attempt after hours) were replaced by someone from the same cluster of health insurance company, sex, and area.

The health survey elicited information about sociodemographic and other personal characteristics: education, living situation, environment, and income. Functional status was assessed by means of the Medical Outcomes Study 36-Item Short Form Health Survey (MOS SF-36).9,10 Chronic diseases and comorbidities were reported, combining information from open questions and from a standardized questionnaire. ${ }^{11}$ Because an internal health locus of control is associated with lower use of care, ${ }^{12}$ we used the "health locus of control questionnaire" (short-form) to elicit the extent of internal orientation.

Detailed data on all medical interventions during 1994 and 1995 provided information on utilization profiles for every respondent. In this article we used the data on total costs reimbursed by the health insurance companies for ambulatory and hospital care.

Although different measures of continuity of care are available, ${ }^{13,14}$ they generally provide similar results. In this study, continuity of care was calculated on the basis of regular (not after-hours) encounters (office and home visits). The total number of different family physicians visited by a single patient could be assessed 


\begin{tabular}{|c|c|c|c|}
\hline Variable & $\begin{array}{c}1 \text { Family } \\
\text { Physician } \\
(\mathrm{n}=2,285)\end{array}$ & $\begin{array}{c}>1 \text { Family } \\
\text { Physician } \\
(n=1,849)\end{array}$ & $P$ Value \\
\hline Age, mean years & 69 & 68 & .140 \\
\hline Sex: female, \% (n) & $50(1,145)$ & $54(992)$ & .024 \\
\hline Region: in Liège, \% (n) & $44(1,011)$ & $55(1,019)$ & $<.001$ \\
\hline Living situation: alone, \% (n) & $29(653)$ & $28(523)$ & .890 \\
\hline Education: higher secondary, \% (n) & $23(530)$ & $22(413)$ & .526 \\
\hline Locus of control: internal, \% (n) & $48(1,101)$ & $47(867)$ & .416 \\
\hline Income: difficulties, \% (n) & $16(360)$ & $20(367)$ & .001 \\
\hline Environment: urban, \% (n) & $16(353)$ & $19(346)$ & .005 \\
\hline Health insurance company: B, \% (n) & $48(1,095)$ & $55(1,015)$ & $<.001$ \\
\hline Chronic disease: > 1, \% (n) & $53(1,216)$ & $60(1,118)$ & $<.001$ \\
\hline \multicolumn{4}{|l|}{ MOS SF-36 dimensions* } \\
\hline Physical functioning & $65( \pm 30)$ & $60( \pm 33)$ & $<.001$ \\
\hline Social functioning & $80( \pm 26)$ & $75( \pm 28)$ & $<.001$ \\
\hline Role limitations (physical) & $67( \pm 42)$ & $62( \pm 43)$ & $<.001$ \\
\hline Role limitations (emotional) & $79( \pm 37)$ & $74( \pm 40)$ & $<.001$ \\
\hline Mental health & $69( \pm 21)$ & $64( \pm 22)$ & $<.001$ \\
\hline Energy & $58( \pm 23)$ & $53( \pm 24)$ & $<.001$ \\
\hline Pain & $68( \pm 28)$ & $62( \pm 30)$ & $<.001$ \\
\hline General health & $58( \pm 20)$ & $54( \pm 23)$ & $<.001$ \\
\hline Change in health status & $46( \pm 18)$ & $44( \pm 20)$ & $<.001$ \\
\hline 1 or more specialist consultations, \% & 77 & 85 & $<.001$ \\
\hline
\end{tabular}

number of encounters with a family physician was brought into the analysis and controlled for. Because the health interview survey is a cross-sectional registration, whereas the utilization of care was registered over the course of 2 years, we performed the same analyses on utilization of care for the time period ( 3 months) of the interview.

\section{RESULTS}

Table 1 compares, for some determinants of utilization of care and for functional status, 2 groups of patients (irrespective of solo or group practice) with a minimum of 2 regular encounters: 1 group with observed provider continuity ( 1 family physician) and 1 group without (more than 1 family physician).

Patients consulting different family physicians were more often women $(P<.05)$, were more likely to have financial problems $(P \leq .001)$, and more often living in an urban environment $(P<.01)$. Patients without provider continuity were more fre-

by means of physician identification numbers. In this study a minimum of 2 regular encounters with a family physician during the 2 years was taken as the lowest threshold for inclusion in the analysis: 4,134 respondents met this criterion and were divided into 2 subgroups based on the number of physicians from whom care was sought in 1994 and 1995. Two cohorts were constituted. Patients who always contacted the same family physician were defined as having provider continuity. If more than 1 general practitioner was visited, patients were categorized as having no provider continuity.

Bivariate analyses, with total health care costs by provider continuity, were performed. Because of the highly skewed distribution of costs of care, we used the median scores instead of the arithmetic means. Significance of differences was measured by means of nonparametric tests. To measure the effect of provider continuity on the use of health care resources, taking into account other relevant utilization determinants, a multivariate linear regression analysis was undertaken with the (logarithmic transformation of) total health care cost as the dependent variable.

The more encounters, the greater the risk of having seen more than 1 family physician. Accordingly, the quently members of health insurance company B. Sixty percent of the patients who were seeing more than 1 family physician reported more than 1 chronic disease compared with $53 \%$ of the patients with only 1 general practitioner. The health status and the functional status of the 2 groups were significantly different. Patients without provider continuity registered a significantly lower score (worse) on different dimensions of functional status. Comorbidity is a typical feature of older patients, and patients with comorbid conditions are at increased risk of an impaired functional capacity. ${ }^{15}$ In subsequent analysis we used only 2 of the SF-36 scales (physical and mental functioning) and the multiple morbidity indicator to avoid a high degree of multiple collinearity among the explanatory variables.

Table 2 shows the results of the bivariate analyses. Total health care costs (median values) were calculated in each of the groups. Older patients, women, patients living in Liège, patients living alone, and those with less education had higher health care costs. Patients with an internal locus of control or with no financial problems had significantly lower costs. Costs were higher for those in urban areas. Those with 1 or more of the 3 selected morbidity indicators had much higher costs. Respondents without provider continuity scored 


\begin{tabular}{|c|c|c|}
\hline Determinants & $\begin{array}{l}1 \text { Family Physician } \\
(n=2,285) \\
\in(n)\end{array}$ & $\begin{array}{c}>1 \text { Family Physician } \\
(\mathrm{n}=1,849) \\
\in(\mathrm{n})\end{array}$ \\
\hline $\begin{array}{l}\text { Age, years } \\
45-64 \\
65-74 \\
75+ \\
P \text { value* }\end{array}$ & $\begin{array}{l}218(690) \\
329(804) \\
435(791) \\
<.001\end{array}$ & $\begin{array}{l}324(641) \\
524(580) \\
970(627) \\
<.001\end{array}$ \\
\hline $\begin{array}{l}\text { Sex } \\
\text { Men } \\
\text { Women } \\
P \text { value }^{\dagger}\end{array}$ & $\begin{array}{l}297(1,140) \\
338(1,145) \\
.029\end{array}$ & $\begin{array}{l}438(857) \\
581(992) \\
.07\end{array}$ \\
\hline $\begin{array}{l}\text { Region } \\
\text { Aalst } \\
\text { Liège } \\
P \text { value }\end{array}$ & $\begin{array}{l}281(1,274) \\
351(1,011) \\
.009\end{array}$ & $\begin{array}{l}462(830) \\
561(1,019) \\
.418\end{array}$ \\
\hline $\begin{array}{l}\text { Living situation } \\
\text { Alone } \\
\text { Not alone } \\
P \text { value }^{\dagger}\end{array}$ & $\begin{array}{l}393(653) \\
290(1,627) \\
<.001\end{array}$ & $\begin{array}{l}775(523) \\
440(1,317) \\
<.001\end{array}$ \\
\hline $\begin{array}{l}\text { Education } \\
\text { Lower secondary or less } \\
\text { Higher secondary or more } \\
P \text { value }^{\dagger}\end{array}$ & $\begin{array}{l}328(1,738) \\
288(530) \\
.002\end{array}$ & $\begin{array}{l}585(1,422) \\
374(413) \\
<.001\end{array}$ \\
\hline $\begin{array}{l}\text { Health locus of control } \\
\text { Not internal } \\
\text { Internal } \\
P \text { value }^{\dagger}\end{array}$ & $\begin{array}{l}366(1,184) \\
278(1,101) \\
<.001\end{array}$ & $\begin{array}{l}422(867) \\
645(982) \\
<.001\end{array}$ \\
\hline $\begin{array}{l}\text { Income } \\
\text { No difficulties } \\
\text { Difficulties } \\
P \text { value }^{\dagger}\end{array}$ & $\begin{array}{l}308(1,907) \\
398(360) \\
.002\end{array}$ & $\begin{array}{l}462(1,470) \\
766(367) \\
<.001\end{array}$ \\
\hline $\begin{array}{l}\text { Health insurance company } \\
\text { A } \\
\text { B } \\
P \text { value }^{+}\end{array}$ & $\begin{array}{l}320(1,190) \\
318(1,095) \\
.184\end{array}$ & $\begin{array}{l}487(834) \\
535(1,015) \\
.282\end{array}$ \\
\hline $\begin{array}{l}\text { Environment } \\
\text { (Semi) rural } \\
\text { Urban } \\
P \text { value }^{\dagger}\end{array}$ & $\begin{array}{l}306(1,886) \\
399(353) \\
.010\end{array}$ & $\begin{array}{l}487(1,463) \\
626(346) \\
.014\end{array}$ \\
\hline $\begin{array}{l}\text { Physical functioning } \\
\leq 80 \text { (bad) } \\
>80 \text { (good) } \\
P \text { value }^{\dagger}\end{array}$ & $\begin{array}{l}407(1,363) \\
210(896) \\
<.001\end{array}$ & $\begin{array}{l}761(1,166) \\
275(655) \\
<.001\end{array}$ \\
\hline $\begin{array}{l}\text { Mental functioning } \\
\leq 80 \text { (bad) } \\
>80 \text { (good) } \\
P \text { value }^{\dagger}\end{array}$ & $\begin{array}{l}353(1,542) \\
241(705) \\
<.001\end{array}$ & $\begin{array}{l}604(1,385) \\
337(450) \\
<.001\end{array}$ \\
\hline $\begin{array}{l}\text { Multiple morbidity } \\
0 \text { or } 1 \text { chronic disease } \\
>1 \text { chronic disease } \\
P \text { value }^{\dagger}\end{array}$ & $\begin{array}{l}219(1,069) \\
425(1,216) \\
<.001\end{array}$ & $\begin{array}{l}295(731) \\
782(1,118) \\
<.001\end{array}$ \\
\hline
\end{tabular}

physical functioning, and multiple morbidities, Table 3 shows the significant contribution of provider continuity: provider continuity is associated with a lower total health care cost after controlling for a wide variety of sociodemographic and other patient characteristics, including morbidity. Another remarkable finding is the association of an internal health locus of control with lower cost.

An analysis of utilization of care and the costs during the 3-month interview period confirmed the association between provider continuity and lower total health costs.

\section{DISCUSSION}

Continuity of care has often been studied in relation to patient satisfaction, ${ }^{16}$ specific health problems such as epilepsy, ${ }_{1}^{17}$ or use of resources in the consultation. ${ }^{18}$ Others found that lack of continuity is associated with higher morbidity, difficult consultations, nonattendance, and an increase of utilization of open-access clinics. ${ }^{19}$

Until now, few studies ${ }^{4,5}$ have investigated the relationship between provider continuity with the family physician and total costs of health care while controlling for differences in morbidity. Our study adds strong evidence to the conclusion that provider continuity with a family physician might be cost saving. Although the total costs are explained by patients who lack continuity having more sickness and more encounters (which probably implies more visits to specialists and more hospitalizations), the remarkable finding is the independent role of low continuity with a family physician in relation to total health care costs.

There are some limitations in this study. Generalizability probably cannot be assumed, as the study was limited to adults aged 45 years and older from 2 insurance providers and 2 regions. A second constraint is the lack of information with respect to

systematically higher for costs than respondents who visited only 1 family physician.

Using other determinants of utilization, a multivariate linear regression analysis was performed to take into account the differences in Table 2: $27.6 \%$ of the variance in total health care costs could be explained by the variables in the model. Apart from the well-known factors related to total health care costs, such as age, the physicians. From the literature and from previous research, we know that physician characteristics contribute in an important way to the explanation of medical care utilization. ${ }^{20}$ The impact of physician characteristics could not be investigated in this study and would be worthwhile to explore in further research. The training of the physician, continuing medical education, attitudes (eg, defensiveness), personal back- 


\begin{tabular}{|lcr|}
\hline \multicolumn{3}{|c|}{ Table 3. Provider Continuity (0/1) in a Multivariate } \\
Approach With Total Health Care Cost (Logarithmic \\
Transformation) as the Dependent Variable: \\
Standardized Regression Coefficients $\beta$ \\
\hline \multicolumn{4}{|c}{$\begin{array}{c}\text { Standardized } \\
\text { Regression } \\
\text { Coefficient } \beta\end{array}$} & P Value \\
Explaining Variables & .086 & $<.001$ \\
Older age & -.036 & .008 \\
Sex (male) & -.030 & .029 \\
Health locus of control: internal & -.1568 & $<.001$ \\
Physical functioning & -.056 & $<.001$ \\
Mental functioning & .116 & $<.001$ \\
Multiple morbidity & .296 & $<.001$ \\
Number of regular encounters & -.105 & $<.001$ \\
Provider continuity & $27.6 \%$ & \\
\hline$R^{2}$ & & \\
\hline
\end{tabular}

ground, practice organization, and sex, all certainly influence the implementation of evidence-based medicine, communication skills, use of technical investigations, prescription of generic drugs, frequency of follow-up appointments, and referral pattern.

The main purpose of this study was to investigate the association of provider continuity with the family physician and the total cost of health care. It became quite clear from the bivariate analyses that patients who were visiting the same family physician had a lower total cost of medical care. The added value of the actual study is that, by using a multivariate design (linear multivariate regression) and taking morbidity into account, we were able to show provider continuity in family medicine remains one of the most important explaining variables of total health care costs (including costs for specialist visits and hospitalizations). This conclusion of an analysis performed at the micro level confirms the results of previous research at the macro level. ${ }^{1}$

This study contributes to the health policy debate on the importance of instruments contributing to increased provider continuity at the primary care level (eg, a patient list with family physicians), an issue on the actual agenda in different countries both in North America and in Europe.

To read commentaries or to post a response to this article, see the online version at http://annfammed/cgi/content/full/1/3/144.

\section{Financial support}

This study has been sponsored by a grant from the National Health Insurance Institute (R.I.Z.I.V.).

\section{Acknowledgments}

The authors are grateful to Barbara Starfield, MD, MPH, University Distinguished Professor, Department of Health Policy and Management, The Johns Hopkins Medical Institutions (Baltimore, Md, USA), for her help and feedback on a previous version of the article. We thank M. Van Risseghem for administrative assistance in the preparation of the article.
Key words: Community health services; delivery of health care; health services research; provider continuity

Submitted February 4, 2003; submitted revised July 2, 2003; accepted July 5, 2003.

\section{References}

1. Starfield B. Primary care and health. A cross-national comparison. JAMA 1991;266(16):2268-2271.

2. van Weel C. Primary care: political favourite or scientific discipline? Lancet 1996;348:1431-1432.

3. Starfield B. Primary Care: balancing health needs, services and technology. New York, NY: Oxford University Press; 1998:143.

4. Flint S. The impact of continuity of care on the utilization and cost of pediatric care in a Medicaid population [dissertation]. Chicago, Ill: University of Chicago; 1987.

5. Gill J, Mainous A. The role of provider continuity in preventing hospitalizations. Arch Fam Med 1998;7:352-357.

6. Sox CM, Swartz K, Burstin HR, Brennan TA. Insurance or a regular physician which is the most powerful predictor of health care? Am J Public Health 1998;88:364-369.

7. De Maeseneer J, De Prins LF, Heyerick JP, Mambourg F. De trouw van Belgische patiënten aan hun huisarts. Ned Tijdschr Geneeskd 1994; 138:2649-2654.

8. Flocke S, Stange K, Zyzanski S. The impact of insurance type and forced discontinuity on the delivery of primary care. J Fam Pract 1997;45:129-135.

9. McHorney CA, Ware JE Jr, Lu JF, Sherbourne CD. The MOS 36-Item Short-Form Health Survey (SF-36): III. Tests of data quality, scaling assumptions and reliability across diverse patient groups. Med Care 1994;32:40-66.

10. Dixon P, Heaton J, Long A, Warburton A. Reviewing and Applying the SF-36. In: Outcomes briefing. Leeds, UK: UK Clearing House on Health Outcomes- Nuffield Institute for Health; 1994;4:3-25.

11. GAM van den Bos. Zorgen van en voor chronisch zieken [Care for the chronically ill] [PhD thesis]. Utrecht: Bohn Scheltema en Holkema; 1989: 178.

12. Bates MS, Rankin-Hill L. Control, culture and chronic pain. Soc Sci Med 1994;39:629-645

13. Eriksson EA, Mattsson LG. Quantitative measurement of continuity of care. Measures in use and an alternative approach. Med Care 1983; 21:858-875.

14. Ejlertsson G, Berg S. Continuity-of-Care Measures. An analytic and empirical comparison. Med Care 1984;22:231-239.

15. Van Weel C. Chronic diseases in general practice: the longitudinal dimension. Eur J Gen Pract 1996;2:17-21.

16. Hjortdahl P, Laerum E. Continuity of care in general practice: effect on patient satisfaction. BMJ 1992;304:1287-1290.

17. Freeman GK, Richards SC. Personal continuity and the care of patients with epilepsy in general practice. $\mathrm{Br} J$ Gen Pract 1994;44:395-399.

18. Hjortdahl P, Borchgrevink CF. Continuity of care: influence of general practitioners' knowledge about their patients on use of resources in consultations. BMJ 1991;303:1181-1184.

19. Sweeney KG, Gray DP Patients who do not receive continuity of care from their general practitioner - are they a vulnerable group? $\mathrm{Br} J$ Gen Pract 1995;45:133-135.

20. De Maeseneer J. Huisartsgeneeskunde: een verkenning - Een explorerend onderzoek bij huisartsen-stagebegeleiders aan de R.U.Gent [Family Medicine: an exploration with trainers in family medicine] [PhD thesis]. Ghent, Belgium: Ghent University: Department of Family Medicine; 1989. 